\title{
Minimal fat renal angiomyolipoma with lymph node involvement: A case report and literature review
}

\author{
Guangxiang Liu, MD; Dongwei Yao, MD; Shiwei Zhang, MD; Xiaozhi Zhao, MD; Tieshi Liu, MD; \\ Xiaogong Li, MD; Hongqian Guo, MD
}

Department of Urology, Naniing Drum Tower Hospital, The Affiliated Hospital of Nanjing University Medical Schoo, Nanjing Medical University, China

Guangxiang Liu and Dongwei Yao equally contributed to this study.

Cite as: Can Urol Assoc J 2015;9(7-8):E568-71. http://dx.doi.org/10.5489/cuai.2749 Published online August 10, 2015.

\section{Abstract}

Renal angiomyolipomas (AML), consisting of fatty tissue, blood vessels, and smooth muscular cells in various proportions, is a relatively common benign renal neoplasm. Simultaneous involvement of the kidney and lymph nodes is uncommon and might be confused with an advanced renal cancer. AML is divided into minimal fat $A M L$ and fat-predominant AML. However, minimal fat AML with lymph node involvement is extremely rare and difficult to differentiate from RCC on images. We report such a case and review the literature.

\section{Introduction}

Renal angiomyolipoma (AML) is the most common benign solid renal mass and contains fatty tissue, blood vessels, and muscular cell in various proportions. ${ }^{1}$ An uncommon $\mathrm{AML}$ variant is the minimal fat renal $\mathrm{AML}$, which does not present macroscopic fat; thus, it can be difficult to distinguish it from renal cell carcinoma (RCC) on imaging. ${ }^{2}$ There is currently no clear evidence of involvement of regional limphatics in minimal fat renal $\mathrm{AML}$, although recent studies suggested that AML might involve to peri-renal or renal sinus fat, regional lymphatics, ${ }^{3,4}$ and other visceral organs, as well as inferior vena cava..$^{5-7}$

We review the available literature and report a case of invasive minimal fat renal $\mathrm{AML}$ involving regional lymph nodes. To the best of our knowledge, this is the first minimal fat renal AML with regional lymph nodes involvement reported in the literature.

\section{Case report}

A 59-year-old woman presented with a left renal mass detected incidentally on a health screening ultrasound.
There was no history of tuberous sclerosis. Ultrasonographic examination revealed a $3.0-\mathrm{cm}$ isoechoic mass at the left kidney. A computed tomography (CT) scan of the abdomen revealed a 3.0-cm solid tumour of the left kidney (Fig. 1a) and multiple para-aortic lymph nodes (Fig. 1b). The mass was hyper-attenuating on unenhanced-CT scan, with a density value of 47 Hounsfield units (HU). The tumour was enhanced heterogeneously after intravenous injection of iohexol, with values of $81 \mathrm{HU}$ (Fig. 1c). The lymph nodes were slightly enhanced with attenuation values of $60 \mathrm{HU}$ (Fig. 1d). The R.E.N.A.L. Nephrometry Score was 6 points $(1+1+1+a+3)$ (Fig. 1e). The right kidney was normal. There was no evidence of metastasis. The presumptive diagnosis was RCC. A left partial nephrectomy and a para-aortic lymphadenectomy were performed through retroperitoneal laparoscopy without complications.

The solid tumour measured $3.5 \times 3.0 \times 2.0 \mathrm{~cm}$, and had a white-grey cut surface. Histological examination revealed that the major components of the tumour were smooth muscle cells, blood vessels, with only small amounts of fat (Fig. 2a). Para-aortic lymph nodes were positive for AML (Fig. 2b). Immunohistochemical studies showed tumour cells positive for human melanosome-associated protein (HMB-45) (Fig. 2c). During the last 2 years, the patient has been well and an abdominal CT scan revealed no evidence of local recurrence.

\section{Discussion}

Renal AML is sporadic in $80 \%$ of patients, while the remaining $20 \%$ are associated with tuberous sclerosis. ${ }^{8}$ Classical renal AML occurs predominantly in females. ${ }^{9}$ Most cases are found incidentally by widespread use of ultrasound, and some cases may present with symptoms, such as a mass, flank pain, macroscopic hematuria or spontaneous rupture, and subsequent hemorrhage.

Renal AML lymph node involvement has been presented in regional lymph nodes. ${ }^{3,4}$ This leads us to understand 


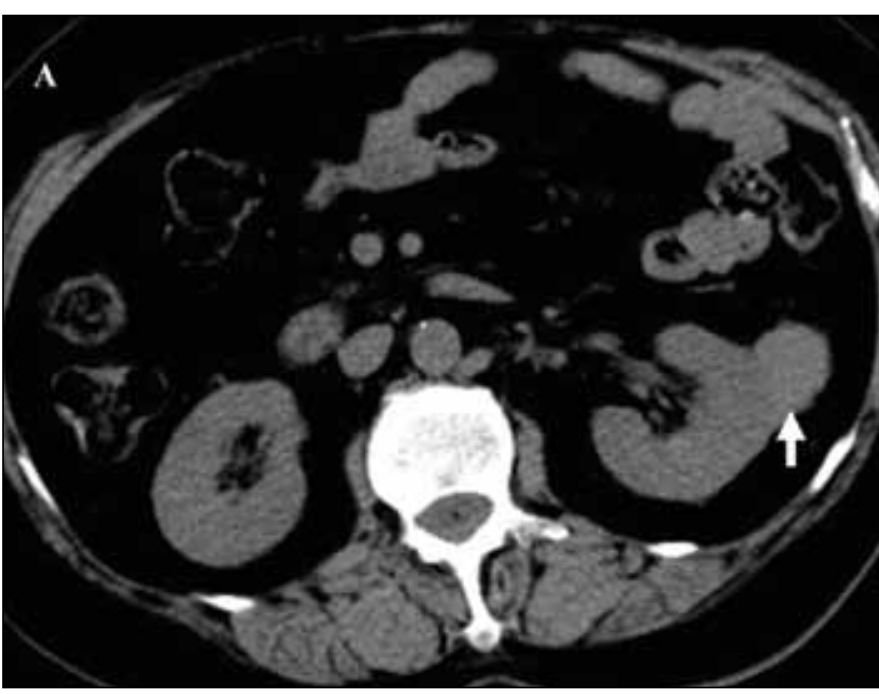

Fig. 1a. The anterior location of renal mass was hyper-attenuating on unenhanced computed tomography scan (arrow).

that simultaneous growth in the kidney and regional lymph nodes are multicentric rather than metastatic. Our literature review showed that there are more than 40 reported cases in the literature to date. No evidence of local recurrence and distant metastasis was found in our reported patient at the 2-year follow-up. Previous studies have demonstrated that no local recurrence or distant metastasis were present after complete resection. ${ }^{5,10}$ The true incidence of positive lymph nodes in patients with renal AML or minimal fat renal AML remains unknown, because regional lymph nodes dissection is rarely performed with this tumour type.

Histopathologically, AML is composed of mature adipose cell, smooth muscle cell, and thick-walled vessels. It is categorized into minimal fat AML and fat-predominant AML. ${ }^{1}$ The minimal fat AML may be impossible to distinguish from

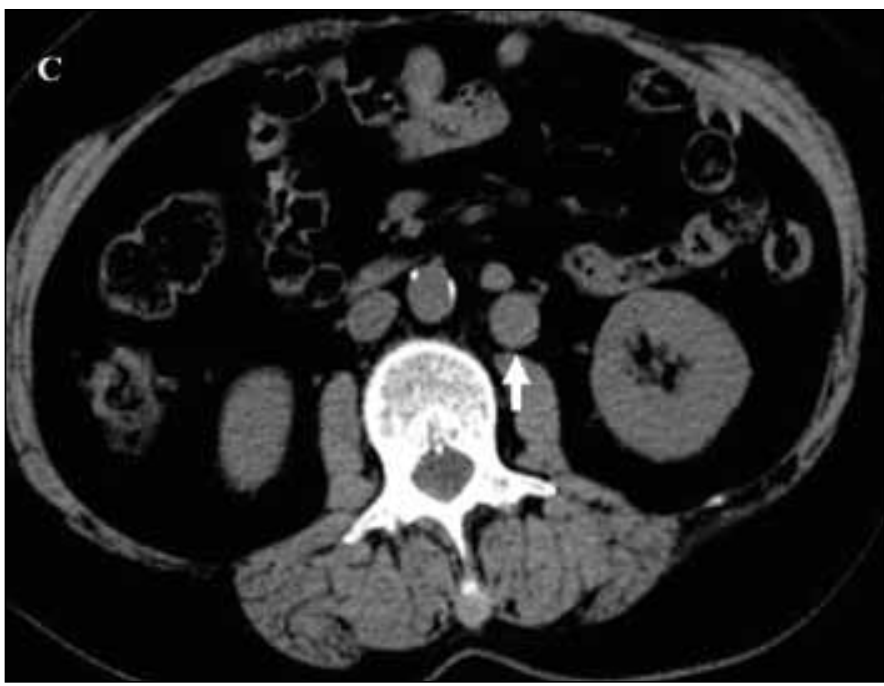

Fig. 1c. The renal mass was enhanced heterogeneously on contrast-enhanced computed tomography image (arrow).

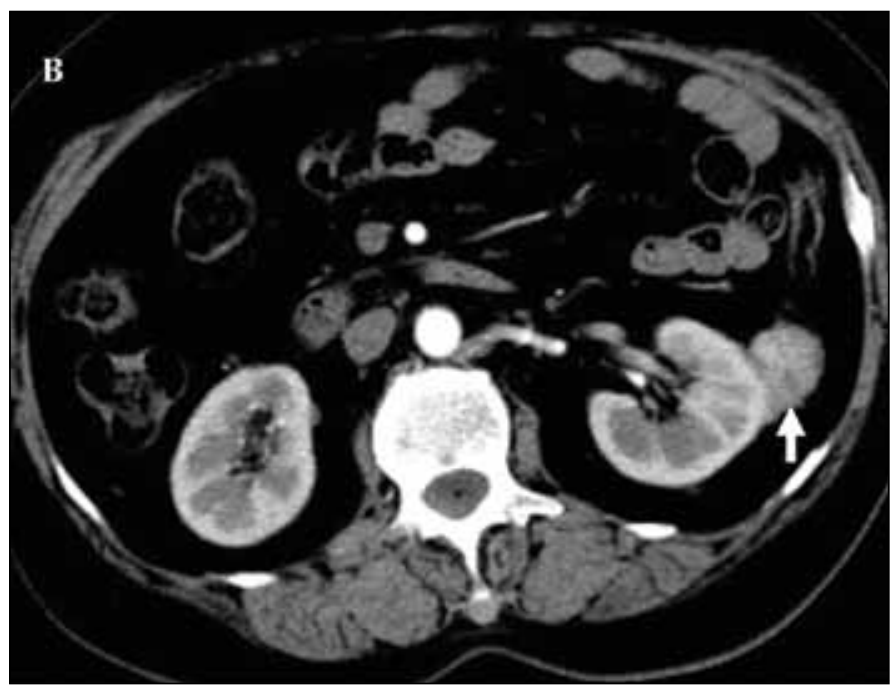

Fig. 1b. Multiple perihilar lymph nodes were identified on unenhanced computed tomography imaging (arrow).

RCC preoperatively. Therefore, most patients with minimal fat AML are confirmed by pathological examination postoperatively. ${ }^{12}$ Recently studies ${ }^{13}$ showed that immunohistochemical analysis with HMB-45 is useful in differentiating between AML and other neoplasm of the kidney. Our immunohistochemical results revealed that positive of HMB-45 are present both in renal mass and in lymph nodes.

Previous studies ${ }^{14}$ have shown that the minimal fat renal AML were hypoechoic on conventional ultrasound (CUS) and slow enhancement of the tumour on contrastenhanced ultrasonography (CEUS). In our patient, the mass was isoechoic on CUS and simultaneous enhancement on CEUS, which were mainly present in RCC. These demonstrated that the echogenicity of the minimal fat AML depends on the proportion of fat in the renal mass.

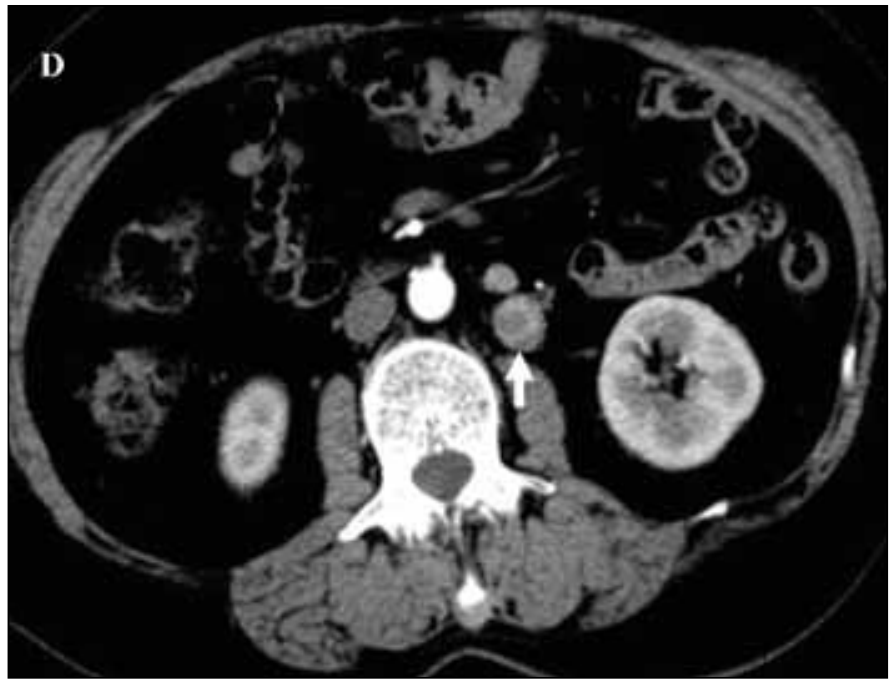

Fig. 1d. The lymph nodes were slightly enhanced on enhanced computed tomography scan (arrow). 


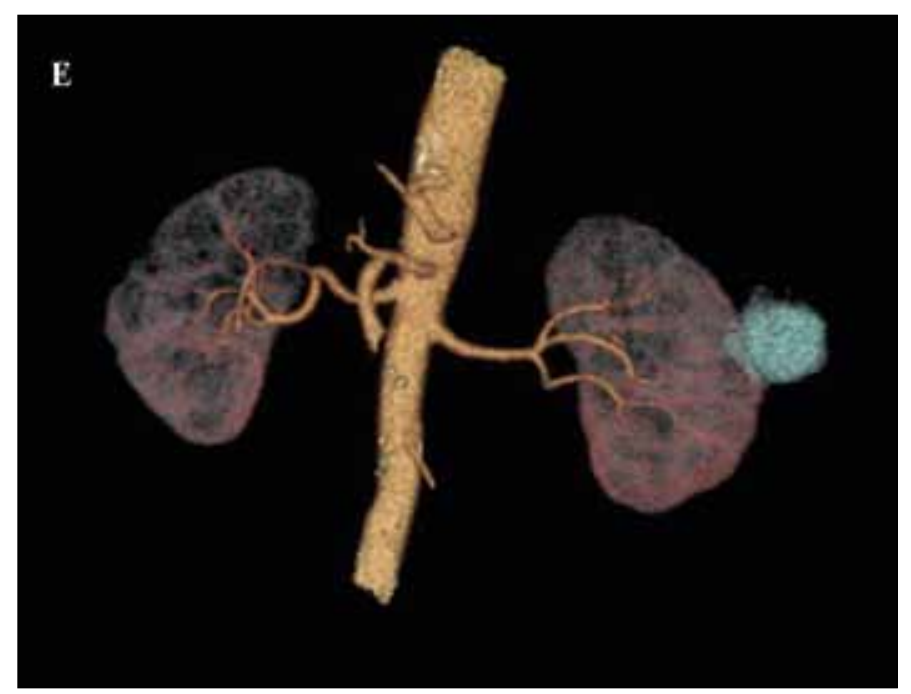

Fig. 1e. Three-dimensional reconstruction of the kidney and renal mass.

Typical AML by CT scans appeared as a well-defined hypo-attenuation in the renal parenchyma on unenhanced CT images. The presence of fat, which should enhance less than $10 \mathrm{HU}$, is diagnostic for renal AML. ${ }^{11}$ Previous investigators have described the imaging findings of AML with minimal fat present hyper-attenuation in the tumour parenchyma on unenhanced CT scans and homogeneous enhancement on contrast material-enhanced CT scans. ${ }^{15-17}$ However, it is sometimes difficult to differentiate AML with minimal fat from RCC, and minimal fat renal AML with lymph node involvement in particular. The mass of our patient was hyper-attenuating on unenhanced-CT scan, and enhanced heterogeneously after a contrast medium injection. Therefore, the patient was diagnosed as RCC with lymph node involvement preoperatively.

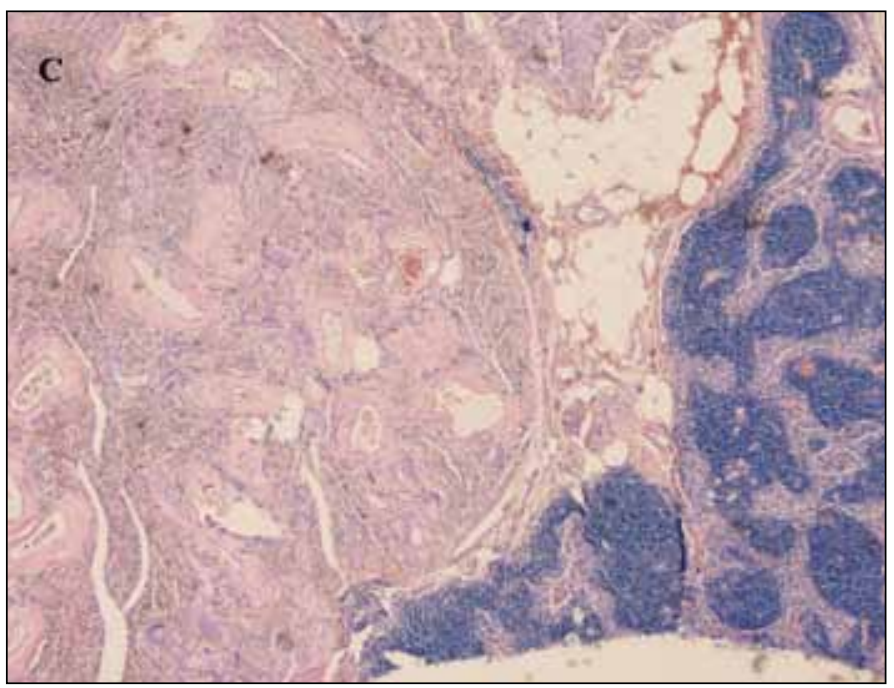

Fig. 2b. Lymph node with involvement by a minimal fat renal angiomyolipomas (hematoxylin and eosin stain $\times 100$ ).

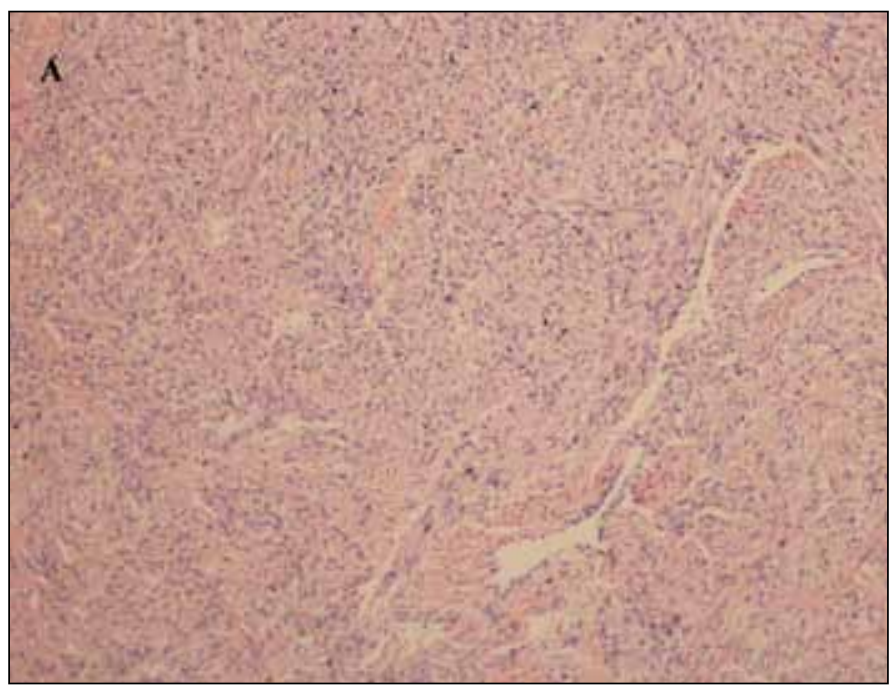

Fig. 2a. Minimal fat renal angiomyolipomas consisted of smooth muscle cells, blood vessels, with only small amounts of fat (hematoxylin and eosin stain $\times 100)$.

The management of renal AML is primarily based on clinical presentation, the size of the mass, bilaterality, and malignant potential. ${ }^{18}$ Recommended therapies include observation, embolization, nephron-sparing surgery (NSS) and nephrectomy. Nephron-sparing surgery is recommended, if possible, in symptomatic tumours smaller than $4 \mathrm{~cm}$. Despite improvements in current imaging method, minimal fat AML with lymph node involvement remains a difficult preoperative diagnosis in some cases. Because a preoperative diagnosis cannot be made with certainty, NSS or nephrectomy with regional lymph nodes dissection should be a therapeutic option.

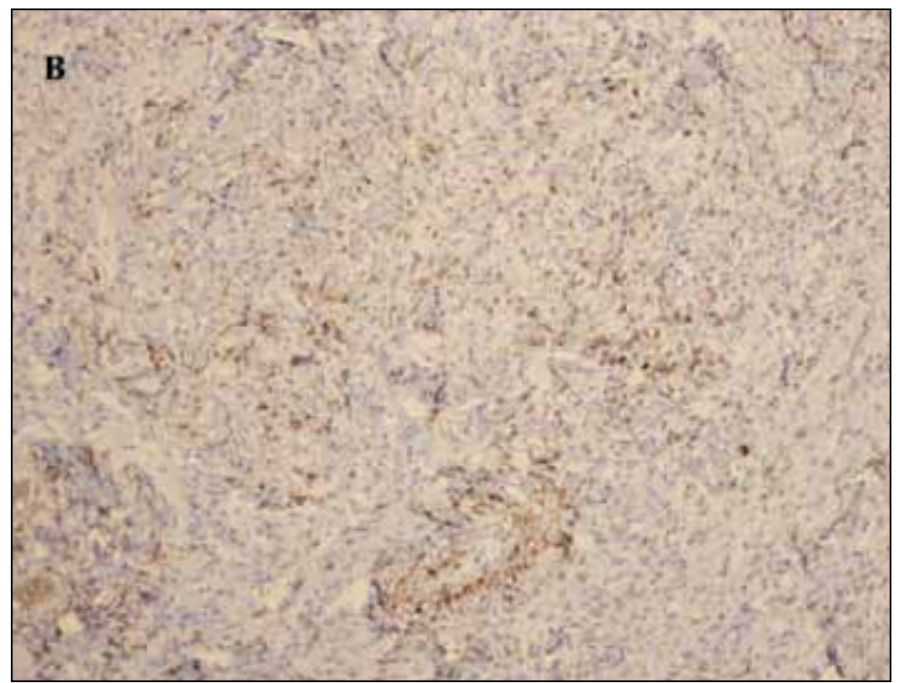

Fig. 2c. HMB-45 positivity cells are seen scattered within the renal mass (immunoperoxdase staining, $\times 100$ ). 


\section{Conclusion}

We have reported an uncommon case of minimal fat AML with lymph node involvement. The minimal fat AML with lymph node involvement is impossible to distinguish from RCC preoperatively, and necessary to confirm the diagnosis by pathology. It is important to raise the clinical awareness of the possibility of unusual lymph node involvement in patients with minimal fat AML. Our patient has had no subsequent clinical problems 2 years after NSS with regional lymphadenectomy. Therefore, we believe that no adjuvant therapy was needed.

Competing interests: The authors all declare no competing financial or personal interests.

This paper has been peer-reviewed.

\section{References}

1. Dickinson $M$, Ruckle $H$, Beaghler $M$, et al. Renal angiomyolipoma: Optimal treatment based on size and symptoms. Clin Nephrol 1998;49:281-6.

2. Liungberg B, Bensalah $\mathrm{K}$, Canfield $\mathrm{S}$, et al. EAU guidelines on renal cell carcinoma: 2014 update. Eur Urol 2015;67:913-24. http://dx.doi.org/10.1016/j.eururo.2015.01.005

3. Frohlich T, Brands A, Thon WF, et al. Angiomyolipoma of the kidney and lymph nodes. World I Urol 1999;17:123-5. http://dx.doi.org/10.1007/s003450050117

4. Turker Koksal I, Tunc M, Kilicaslan I, et al. Lymph nodal involvement by renal angiomyolipoma. Int J Urol 2000;7:386-9. http://dx.doi.org/10.1046/j.1442-2042.2000.00213.x

5. Mittal V, Aulakh BS, Daga G. Benign renal angiomyolipoma with inferior vena cava thrombosis. Urology 2011;77:1503-06. http://dx.doi.org/10.1016/j.urology.2011.01.039.
6. Lopater J, Hartung 0 , Bretelle $F$, et al. Management of angiomyolipoma vena cava thrombus during pregnancy. Obstet Gynecol 2011;117:440-3. http://dx.doi.org/10.1097/A0G.0b013e3181 edbc56.

7. Kaler KS, Rittberg R, Drachenberg DE. Angiomyolipoma with caval extension and regional nodal involvement: Aggressive behaviour or just rare natural history? Case report and review of literature. Can Urol Assoc J 2014;8:E276-8. http://dx.doi.org/10.5489/cuaj.1781.

8. Galluzzo ML, Garcia de Davila MT, Vujanic GM. A composite renal tumor: Metanephric adenofibroma, wilms tumor, and renal cell carcinoma: A missing link? Pediatr Dev Pathol 2012;15:65-70. http:// dx.doi.org/10.2350/11-03- 1007-CR.1.

9. Aydin H, Magi-Galluzzi C, Lane BR, et al. Renal angiomyolipoma: Clinicopathologic study of 194 cases with emphasis on the epithelioid histology and tuberous sclerosis association. Am I Surg Pathol 2009;33:28997. http://dx.doi.org/10.1097/PAS.0b013e31817ed7ab

10. Agarwal R, Agarwal PK, Dalela D. Renal angiomyolipoma with nodal involvement. A 20 year follow up. Br J Urol 1995;76:517. http://dx.doi.org/10.1111/i.1464-410X.1995.tb07765.x

11. Lu Q, Li CX, Huang BJ, et al. Triphasic and epithelioid minimal fat renal angiomyolipoma and clear cell renal cell carcinoma: Qualitative and quantitative CEUS characteristics and distinguishing features. Abdom Imaging 2015;40:333-42. http://dx.doi.org/10.1007/s0026 1-014-0221-y

12. Hafron J, Fogarty JD, Hoenig DM, et al. Imaging characteristics of minimal fat renal angiomyolipoma with histologic correlations. Urology 2005;66:1155-9. http://dx.doi.org/10.1016/i.urology.2005.06.119

13. Pea $M$, Bonetti $F$, Zamboni $G$, et al. Melanocyte-marker-HMB-45 is regularly expressed in angiomyolipoma of the kidney. Pathology 1991;23:185-8. http://dx.doi.org/10.3109/00313029109063563

14. Lu $Q$, Wang $W$, Huang $B$, et al. Minimal fat renal angiomyolipoma: The initial study with contrastenhanced ultrasonography. Ultrasound Med Biol 2012;38:1896-901. http://dx.doi.org/10.1016/i. ultrasmedbio.2012.07.014

15. Hosokawa Y, Kinouchi T, Sawai Y, et al. Renal angiomyolipoma with minimal fat. Int I Clin Oncol 2002;7:120-3.

16. Jinzaki $M$, Tanimoto A, Narimatsu Y, et al. Angiomyolipoma: Imaging findings in lesions with minimal fat. Radiology 1997;205:497-502. http://dx.doi.org/10.1148/radiology.205.2.9356635

17. Obuz F, Karabay N, Secil M, et al.Various radiological appearances of angiomyolipomas in the same kidney. Eur Radiol 2000;10:897-9. http://dx.doi.org/10.1007/s003300051031

18. Lane BR, Aydin H, Danforth TL, et al. Clinical correlates of renal angiomyolipoma subtypes in 209 patients: Classic, fat poor, tuberous sclerosis associated and epithelioid. J Urol 2008;180:836-43. http://dx.doi. org/10.1016/i.juro.2008.05.041.

Correspondence: Dr. Hongqian Guo, Naning Drum Tower Hospital, The Affiliated Hospital of Naniing University Medical School, Nanijng Medical University, China; dr.ghq@163.com 